\title{
SECURED DIGITAL NOTICE BOARD
}

\author{
Greeshma Reynold $^{1}$, Jyothi Surendran ${ }^{2}$, Sivaranjini $^{3}$, Ron Mathew Vincent ${ }^{4}$ \\ ${ }^{I}$ Student, Dept. of Electronics and Communication, B.T.C Engineering College, Kochi, Kerala \\ ${ }^{2}$ Student, Dept. of Electronics and Communication, B.T.C Engineering College, Kochi, Kerala \\ ${ }^{3}$ Student, Dept. of Electronics and Communication, B.T.C Engineering College, Kochi, Kerala \\ ${ }^{4}$ Assistant Professor, Dept. of Electronics and Communication, B.T.C Engineering College, Kochi, Kerala
}

\begin{abstract}
Notice boards are unavoidable factor in schools, colleges, companies etc. Traditional notice boards are manual. They are difficult to update. In order to overcome this problem Digital Notice Board has been introduced. It is a microcontroller based project, which can be accessed by the supervising faculty and pupil in charge of this application. This project introduces a application that is used for the updation and correction of this board. Less manual effort is needed. The faculty can updat3e this notice board at anytime from anywhere. This helps to overcome the lack of communication.
\end{abstract}

Keywords_component; formatting; style; styling; insert (key words)

\section{INTRODUCTION}

Wireless communication has announced its arrival on big stage and the world is going mobile. The use of "Embedded System in Communication" has given rise to many interesting applications that ensures comfort and safety to human life. An embedded system is a combination of hardware and software and perhaps other mechanical parts designed to perform a specific function.

Nowadays everyone is familiar with 'notice boards'. A Notice Board is a very essential device in any institution / organization or public utility place like bus stations, railway stations and parks. At present, when information has to be updated in a notice board, it has to be done manually.

Electronic notice board is a common device that is used to display information. Also in present electronic systems, no matter how many displays are present, only a single notice can be sent to all of the notice boards irrespective of their places. Presently almost all electronic notice boards are designed using wired system. One of the drawbacks of the design is the system is inflexible in term of placement. The common notice board cannot be placed anywhere because of the messy wire.

The aim of this project is to develop a wireless notice board that will be used by the faculty in order to display latest information. Wireless electronics notice board is developed as user friendly notice board with wireless concept that offers the flexibility to control the notice board within range of 100 meters. This is a microcontroller based project where datas are transmitted via wireless communication. A ZigBee module is used for transmission and reception of datas.

\section{BLOCK DIAGRAM}

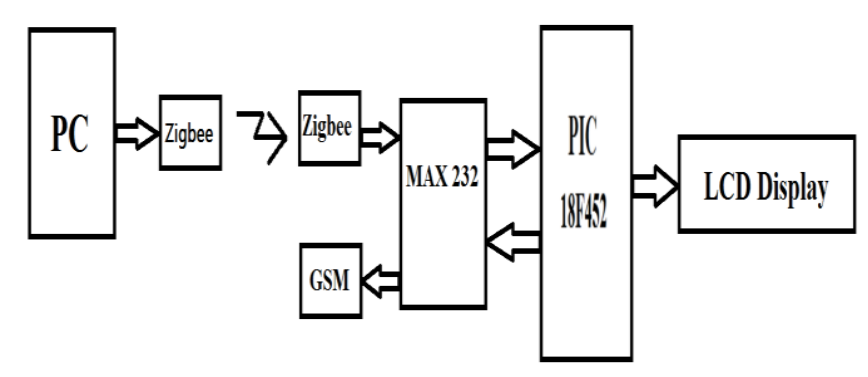

Fig 1: Block Diagram

A PC can be a Laptop or a Desktop with the required software installed in it. MATLAB is the required software to be installed in the PC. The messages to be displayed on the Digital Noticeboard are transmitted from this PC which is under the control of an authorized faculty. A ZigBee module is connected to the PC through which datas are transmitted serially to another ZigBee module which is connected to the PIC18 controller. The later ZigBee module will receive the datas from the former if and only if the baud rates of both the modules are same. A ZigBee module is similar to that of Bluetooth, where ZigBee can ranges up to 100 meters.

When the later ZigBee module receives the data and sends it to the microcontroller via MAX232. A MAX232 is used to setup an asynchronous communication to and from microcontroller to the corresponding modules such as ZigBee, GSM. It is also used as a voltage level shifter .It converts RS232 voltage levels to TTL . The serial port of PC uses RS232 voltage levels, and microcontroller uses TTL levels. To match these voltage levels MAX232 IC is used. 
The Microcontroller is the heart of this project. The datas to be displayed on the LCD are sent to the microcontroller by the PC via ZigBee. Microcontoller stores the data to be displayed and which has to be send to the required people through GSM module.

LCD display is the output device on which the necessary datas are displayed. There is a priority checker used so that the most important and immediate notices can be displayed for a specific time period. In case of an unauthorised used of the PC will results in an alarm along with a warning message to the faculty in charge of the PC. This will avoid the unfair use of manual notice board.

\section{CIRCUIT DIAGRAM}

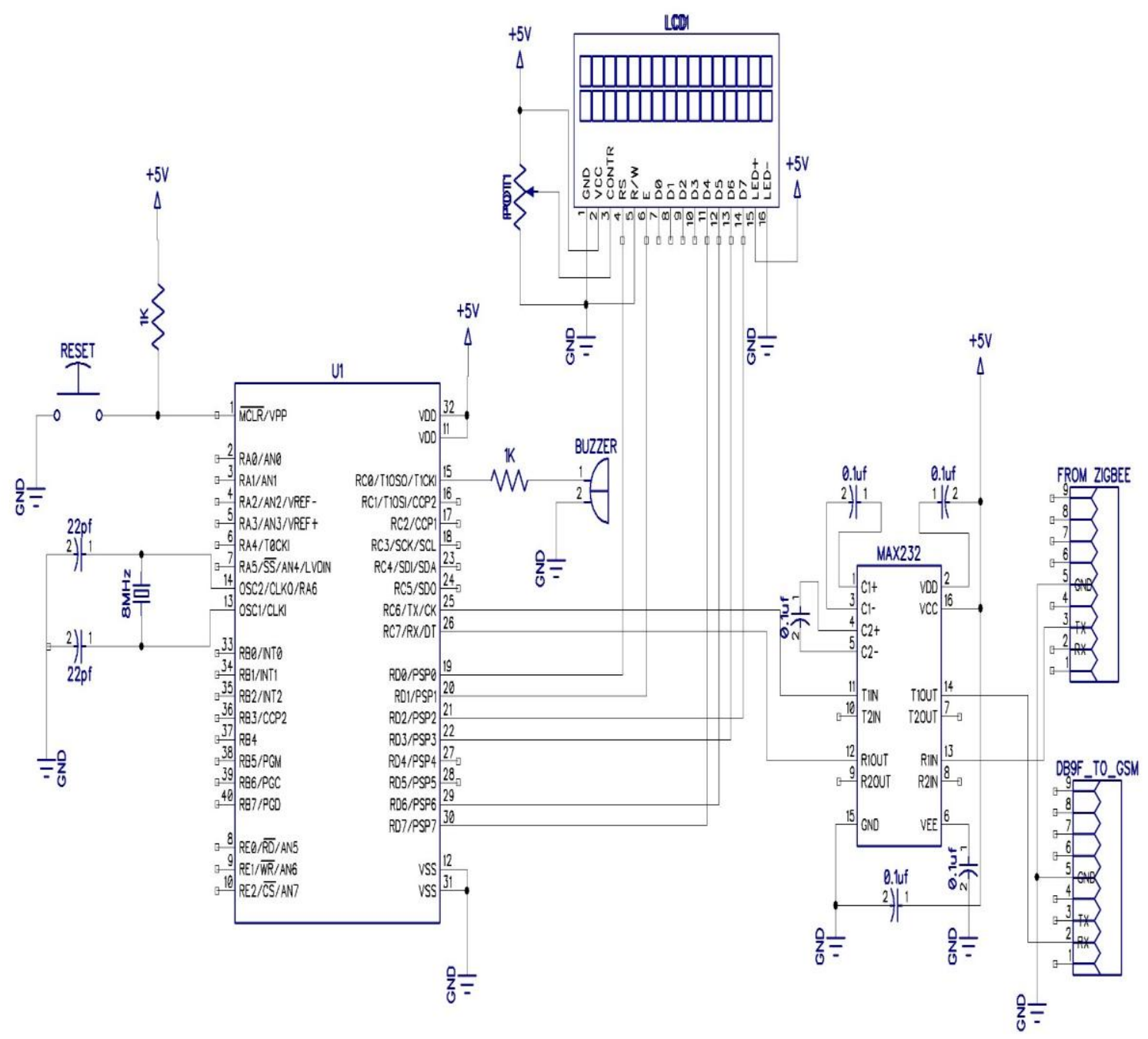

Fig 2: Circuit Diagram

The circuit diagram of the proposed system is shown in the figure above. PIC18F452 acts as the heart of the system. The $\mathrm{PC}$ and a zigbee module acts as the transmitter section. The data's to be displayed on the LCD display are send from the PC via ZigBee module. The PC must be MATLAB software installed, the data's are send from PC through GUI interfacing developed in the MATLAB software. This is provided for security purpose in which the authorized faculty can send the messages only if the password is correct. If there is an unauthorized use of this system the buzzer will be activated and together with that a warning message is send to the authorized faculty. The zigbee in the receiver section receives the data's only if the data rate of both the modules are same.

ZigBee is similar to a bluetooth, which operates at a datarate of $250 \mathrm{kbps}$ at $2.5 \mathrm{GHz}$. The received data is send via the TX pin(3) of zigbee to the R1IN pin(13) of the MAX232 IC. MAX232 is a voltage level converter, it converts the RS232 logic of the PC to the TTL logic of the PIC controller which is transmitted through the R1OUT pin(12) of the MAX232 IC.The voltage level converted signal is received at the RX 
$\operatorname{pin}(26)$ of the PIC18. The controller process the data and displays it via the LCD display.Priority of the messages are checked before sending from the PC.

There are three priorities are set according to our interest. The High priority $(\mathrm{H})$ is set for the messages that are to be displayed urgently, it replaces the current message displayed on the LCD and it is displayed for specific period of time after which the old messsage is displayed again. Similarly in case of Low priority(L), the messages are displayed only after the current message on the noticeboard is overwritten by this message. A Marklist priority(M) is set to display the marklist and the displayed marklist on the noticeboard are made to message format by the pic 18 controller and then it is sent to the corresponding parents mobile numbers through GSM module.

\section{BASIC EXPLANATION}

\subsection{AT Commands}

AT commands are instructions used to control a modem. AT is the abbreviation of ATtention. Every command line starts with "AT" or "at". That's why modem commands are called AT commands. Many of the commands that are used to control wired dial-up modems, such as ATD (Dial), ATA (Answer), ATH (Hook control) and ATO (Return to online data state), are also supported by GSM/GPRS modems and mobile phones.

\begin{tabular}{|c|c|}
\hline \multicolumn{2}{|c|}{ AT commands } \\
\hline Command & Meaning \\
\hline $\mathrm{AT}+\mathrm{CMGS}$ & Send message \\
\hline $\mathrm{AT}+\mathrm{CMSS}$ & $\begin{array}{c}\text { Send message from } \\
\text { storage }\end{array}$ \\
\hline $\mathrm{AT}+\mathrm{CMGR}$ & Receive message \\
\hline
\end{tabular}

\subsection{Embedded C}

Embedded $\mathrm{C}$ is used for microcontroller programming. There is a large and growing - international demand for programmers with 'embedded' skills, and many desktop developers are starting to move into this important area. The reasons to write program in $\mathrm{C}$ is that it is easier to modify and update, codes available in the function libraries can be used and these codes are portable to other microcontrollers.

\subsection{MATLAB}

For more efficient and hasty programming MATLAB is used in which the GUI interfacing was developed to access and monitor the system .A user interface window is created. The programming is done using the in-built functions.

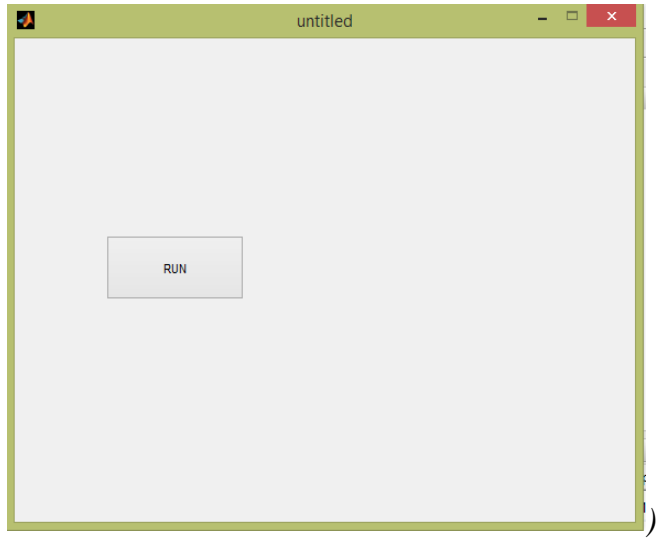

Fig 3: GUI Main Window

The figure shows the main GUI window through which the authorized faculty access the and monitors the notice board. The messages can be send only if the password entered is correct. The priority of the message is also checked and accordingly it is displayed on the noticeboard.

\section{MERITS}

System is user friendly: Messages are only to be typed on a mobile or a computer, which in turn are displayed wirelessly on the display unit.

Usage of printers are avoided: Since usage of papers are not needed to display information, printers are also of no use in this system.

Means of information transmission is faster: There is no delay in transmission of information. Messages are displayed in a matter of seconds after typing.

Long Coverage is provided: Until the required network is available, messages can be send from any part of the world.

\section{FUTURE ENHANCEMENTS}

This technology could be further modified and more upgraded as per individual need and interest. We have discussed some basic ideas of this technology. And depending on innovative applications user can upgrade as per requirement.

\section{ACKNOWLEDGMENTS}

We would like to thank our mentor and guide Prof. Lince Mathew and Asst. Prof. Ron Vincent Mathew for guidance and help throughout our project. We are also thankful to our Institute Baselios Thomas I Catholicose College of Engineering and Technology, Kerala, India for providing all the facilities needed for our project.

\section{REFERENCES}

[1] International Journal of Soft Computing and Engineering (IJSCE) ISSN: 2231-2307, Volume-2, Issue-3, July 2012 by Pawan Kumar, Vikas Bhrdwaj, Kiran Pal, Narayan Singh Rathor, Amit Mishra. 
[2] Advance in Electronic and Electric Engineering ISSN 2231-1297, Volume 3, Number 7 (2013), pp. 827-832 by Foram Kamdar, Anubbhav Malhotra and Pritish Mahadik.

[3] A. Clark and R. Harun, Assessment of kalman-lter channel estimators for an HF radio link," IEEE Proceedings, vol. 133, pp. 513-521, Oct 1986.

[4] IOSR Journal of Computer Science (IOSR-JCE) eISSN: 2278-0661, p-ISSN: 2278-8727 PP 24-29 by Mayur R. Bhoyar, Suraj Chavhan, Vaidehi Jaiswal.

[5] International Journal of Current Engineering and Technology E-ISSN 2277 - 4106, P-ISSN 2347 5161 by N. B. Bhawarkar, G.V. Dehankar, S.P. Nirmal , S.P. Padghan, S.M. Borde,V.V. Kakade and S.K. Tichkule.

[6] International Journal of Emerging Technology and Advanced Engineering Volume 3, Issue 3, March 2013 by Smt.M.Baby, P.Harini, Y.Eleena Slesser, Y.Tejasw, K.Ramajyothi, M.Sailaja, K.Annie Sumantha 